\title{
Modeling of the stress-strain state of the ground mass contaminated with peracetic acid
}

\author{
Anna Levenko ${ }^{1 *}$ \\ ${ }^{1}$ Department of Soil Mechanics, Foundations and Engineering Geology, O. M. Beketov National \\ University of Urban Economy in Kharkiv, 17, Marshal Bazhanov Street, Kharkiv, 61002, Ukraine.
}

\begin{abstract}
None of the methods described previously provides a solution to the problem that deals with the SSS evaluation of the ground mass which is under the influence of chemically active substances and, in particular, under the influence of peracetic acid. The stress-strain state of the ground mass contaminated with peracetic acid was estimated. Stresses occurring in the ground mass in the natural state were determined after the entry of acid into it and after the chemical fixation of it with sodium silicate. All the parameters of the stress-strain state of the ground mass were obtained under a number of physical and mechanical conditions. It was determined that following the work on the silicatization of the ground mass contaminated with peracetic acid the quantity of strain decreased by 26.11 to $48.9 \%$. The comparison of the results of stress calculations indicates the stress reduction in the ground mass in $1.8-2.6$ times after its fixing.
\end{abstract}

\section{Introduction}

Currently, there is a problem resulting from the ground contamination with industrial effluents directly under industrial buildings, which in turn leads to the swelling of ground bases, the shifting of foundations and the destruction of building structures $[1,2,5]$.

Therefore, when designing it is necessary to take into account the swelling effect on the entire "ground base-foundation-building" system for more reliable operation of the structure.

The existing standards $[3,4]$ only regulate the design rules for swelling grounds but do not provide an opportunity to predict the further behavior of the ground base in case of chemical contamination.

In addition, not much is known about the behavior of the swelling grounds after their chemical fixation and the stress-strain state (SSS) of the "fixed ground base-foundation building" system.

\section{Analysis of recent studies and publications}

The solution to the problem taking into account the joint action of the "ground base foundation - building" system is explained in the paper [9]. It is proposed to represent the

\footnotetext{
* Corresponding author: levenkoanna@mail.ru
} 
ground mass consisting of the swelling grounds as a linearly deformable medium, to take into account the swelling of the ground base as an additional action that is close in nature to the influence of temperature, and to consider the swelling ground as a material possessing orthotropic properties.

Some authors [8] believe that the finite element method is the most suitable for evaluating the stress-strain state (SSS) of the "ground base - foundation - building" system. As this takes place, it is recommended to simulate separately each of the parts of the system that makes it possible to see changes in the SSS of system and to adjust the decisions taken while performing work.

In papers $[6,7]$ the methods of accounting for the effect of the ground base swelling on the SSS of the "ground base - foundation - building" system under plane deformation are presented.

Additional pressure caused by the ground swelling as an external load applied to the foundations in the areas of the swelling knoll influence is recommended to be taken into account.

However, none of the methods described previously provides a solution to the problem that deals with the SSS evaluation of the ground mass which is under the influence of chemically active substances and, in particular, under the influence of peracetic acid.

\section{The objectives and tasks of the problem research}

The objective of the research is to assess the stress-strain state of a ground mass contaminated with peracetic acid.

\section{The main part of the research}

The present research has been implemented as a numerical experiment consisting of a series of calculations for various ground conditions; the four types of ground bases with the four calculated behavioral patterns were under research.

Table 1. Values of characteristics of the deformation modulus and the Poisson's ratio.

\begin{tabular}{|c|c|c|c|c|c|c|}
\hline \multirow[b]{2}{*}{ Ground type } & \multicolumn{3}{|c|}{ Poisson's ratio } & \multicolumn{3}{|c|}{ Deformation modulus, $\mathrm{MPa}$} \\
\hline & $\begin{array}{c}\text { Before } \\
\text { fixing } \\
\text { while in } \\
\text { the natural } \\
\text { state }\end{array}$ & $\begin{array}{c}\text { After } \\
\text { raising } \\
\text { the } \\
\text { acid } \\
\text { content } \\
\text { level }\end{array}$ & $\begin{array}{l}\text { After } \\
\text { fixing }\end{array}$ & $\begin{array}{c}\text { Before } \\
\text { fixing } \\
\text { while in } \\
\text { the natural } \\
\text { state }\end{array}$ & $\begin{array}{c}\text { After } \\
\text { raising } \\
\text { the acid } \\
\text { content } \\
\text { level }\end{array}$ & $\begin{array}{l}\text { After } \\
\text { fixing }\end{array}$ \\
\hline $\begin{array}{l}\text { Fine quartz } \\
\text { sand }\end{array}$ & 0.30 & 0.35 & 0.27 & 31.5 & $21.5-22.03$ & 38.9 \\
\hline $\begin{array}{l}\text { Brownish- } \\
\text { yellow sandy } \\
\text { loam with } \\
\text { plastic behavior }\end{array}$ & 0.34 & 0.39 & 0.30 & 22.6 & $19.9-21.9$ & 42 \\
\hline $\begin{array}{c}\text { Heavy clay } \\
\text { loam with hard } \\
\text { plastic behavior }\end{array}$ & 0.36 & 0.41 & 0.30 & 26.7 & $16.9-24.8$ & 38 \\
\hline $\begin{array}{l}\text { Gray semisolid } \\
\text { clay }\end{array}$ & 0.42 & 0.50 & 0.36 & 22.4 & $18.9-21.9$ & 37.9 \\
\hline
\end{tabular}


Basic hypotheses and assumptions are as follows: the model of the ground base is the model of a linearly deformable half-space.

The specified stiffness characteristics are as follows: $E_{i}-$ the deformation modulus, $v_{i}-$ Poisson's ratio, and $P_{i}-$ the load transferred to the ground base.

Linearly deformable medium is considered; the ground mass with the dimensions of $10 \times 10 \mathrm{~m}$ is under the plane deformation. On centre the ground mass perceives a load from the foundation with a width of $1 \mathrm{~m}$ (Area 3 ).

Inside the ground mass there is Area 1 with the dimensions of $5 \times 5 \mathrm{~m}$ subjected to the raising of the acid content level and further fixing. The rest of the ground mass is represented by Area 2.

The following calculation schemes are taken into account:

- the calculation scheme 1. Areas 2, 3 are the grounds with normal (natural) characteristics. Area 3 is the C16/20 concrete foundation. The load on Area 3 is the concentrated force of 100 tons;

- the calculation scheme 2. Area 2 is the ground with normal (natural) characteristics. Area 1 is the ground with the raised acid content levels. Area 3 is the C16/20 concrete foundation. The load on Area 3 is the concentrated force of 100 tons;

- the calculation scheme 3. Area 2 is the ground with normal (natural) characteristics. Area 1 is the ground with the raised acid content level characteristics. Area 3 is the C16/20 concrete foundation made from. The load on Area 3 is the concentrated force of 125 tons;

- the calculation scheme 4. Area 2 is the ground with normal (natural) characteristics. Area 2 is the ground with fixed characteristics. Area 3 is the C16/20 concrete foundation. The load on area 3 is the concentrated force of 125 tons.

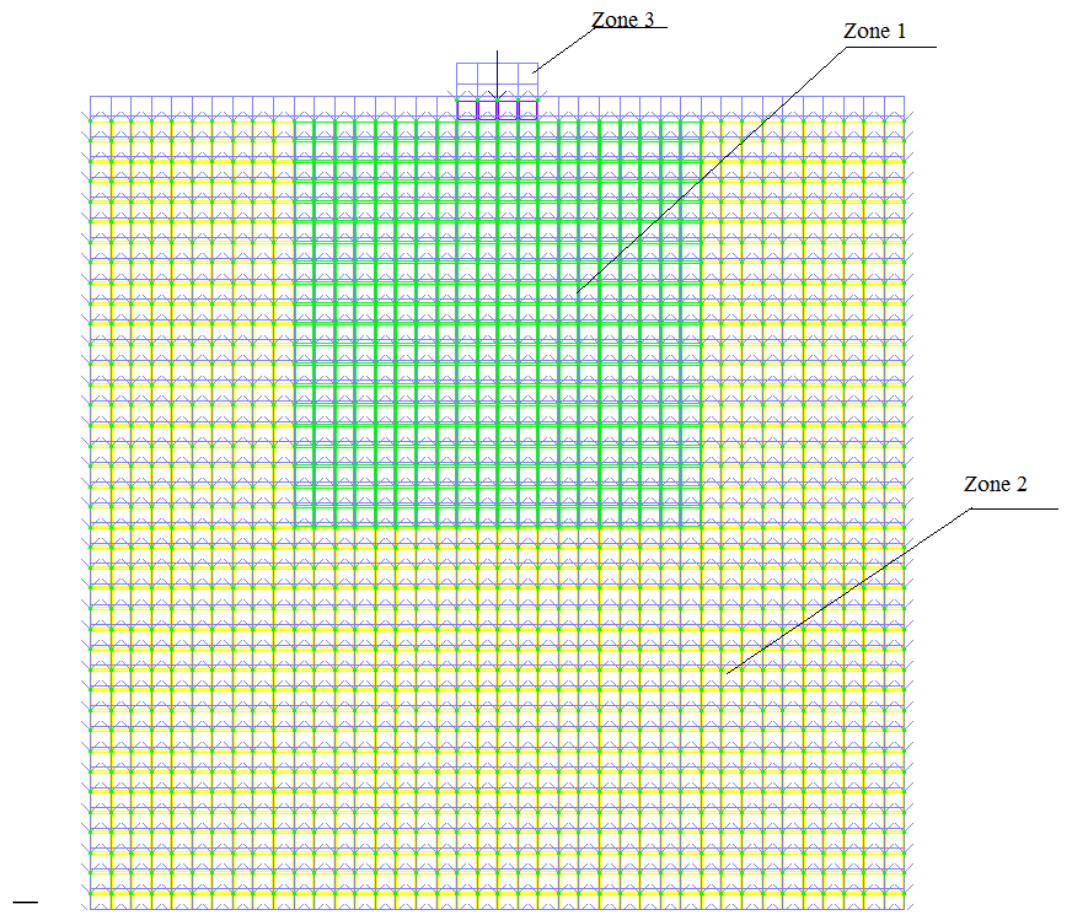

Fig. 1. Finite element model. Area 1 is the ground with the raised acid content level (fixed) characteristics; Area 2 is the ground with natural characteristics; Area 3 is the foundation.

The coordinates of the model points were specified according to the results of the evaluated amount of the calculation scheme deformation. 
Modeling was carried out in the CAD Lira. The finite element model (Fig. 1) was formed from FE21 that was a rectangular element of the linearly deformable medium (beam - wall).

The model included 1.686 points and 1.604 elements. The thickness of elements was arbitrarily set as equal to $1 \mathrm{~m}$.

As a result, the characteristics of the stress-strain state of the ground base were obtained under the four different conditions of contamination and loading.

The main criterion for comparison was taken by the values of shifts along the $\mathrm{X}, \mathrm{Y}$ and $\mathrm{Z}$ axes, as well as the values of stresses arising in the ground mass.

The results of the calculation are illustrated by the fields of vertical shifts of the ground mass (Figure 3) and in a tabular form (Table 2).

Table 2. Stresses and vertical shifts of the ground mass.

\begin{tabular}{|c|c|c|c|c|c|c|}
\hline & & & \multicolumn{4}{|c|}{ Ground type } \\
\hline & & & $\begin{array}{l}\text { Fine quartz } \\
\text { sand }\end{array}$ & $\begin{array}{l}\text { Brownish- } \\
\text { yellow sandy } \\
\text { loam with } \\
\text { plastic } \\
\text { behavior } \\
\end{array}$ & $\begin{array}{l}\text { Heavy clay } \\
\text { loam } \\
\text { with hard } \\
\text { plastic } \\
\text { behavior } \\
\end{array}$ & $\begin{array}{c}\text { Gray } \\
\text { semisolid clay }\end{array}$ \\
\hline \multirow{4}{*}{$\begin{array}{l}\text { Vertical shift of } \\
\text { the ground } \\
\text { mass, mm }\end{array}$} & \multicolumn{2}{|c|}{$C S-1$} & 92 & 128 & 108 & 129 \\
\hline & \multicolumn{2}{|c|}{$C S-2$} & 116 & 134 & 125 & 138 \\
\hline & \multicolumn{2}{|c|}{$C S-3$} & 137 & 158 & 148 & 138 \\
\hline & \multicolumn{2}{|c|}{$C S-4$} & 80,3 & 123 & 108 & 117 \\
\hline \multirow{12}{*}{$\begin{array}{l}\text { Stresses in the } \\
\text { ground mass, } \\
\mathrm{kN} / \mathrm{cm}^{2}\end{array}$} & \multirow{3}{*}{$C S-1$} & $\sigma_{x}$ & -0.0377 & -0.0369 & -0.0366 & -0.355 \\
\hline & & $\sigma_{z}$ & -0.101 & -0.101 & -0.101 & -0.1 \\
\hline & & $\tau_{x z}$ & -0.0679 & -0.0679 & -0.0678 & -0.0678 \\
\hline & \multirow{3}{*}{$C S-2$} & $\sigma_{x}$ & -0.37 & -0.036 & $-0,357$ & $-0,0339$ \\
\hline & & $\sigma_{z}$ & $-0,101$ & $-0,101$ & -0.1 & -0.0998 \\
\hline & & $\tau_{x z}$ & -0.0679 & -0.0678 & -0.678 & -0.0676 \\
\hline & \multirow{3}{*}{$C S-3$} & $\sigma_{x}$ & -0.0462 & -0.045 & -0.447 & -0.0424 \\
\hline & & $\sigma_{z}$ & -0.126 & -0.0126 & -0.125 & -0.125 \\
\hline & & $\tau_{x z}$ & -0.0849 & -0.0847 & -0.847 & -0.845 \\
\hline & \multirow{3}{*}{$C S-4$} & $\sigma_{x}$ & -0.0373 & -0.0368 & -0.369 & -0.0357 \\
\hline & & $\sigma_{z}$ & -0.101 & -0.101 & -0.101 & -0.1 \\
\hline & & $\tau_{x z}$ & -0.0832 & -0.0833 & -0.833 & -0.0832 \\
\hline
\end{tabular}

Table 2 also shows the stresses arising in the ground mass for four ground groups under conditions specified by the calculation schemes (CS) CS-1, CS-2, CS-3 and CS-4. 
From the results of the calculations, the picture (Fig. 2) of the change in the magnitude of the deformation of the ground mass under the four given conditions is clearly visible. After carrying out works on fixing the ground mass contaminated with solutions of peracetic acid the value of deformations decreases

by $48.9 \%$ for grounds with the parameter $L<3 \%$,

by $26.11 \%$ for grounds with the parameter of $L 3-10 \%$,

by $32 \%$ for grounds with the parameter of $L 10-30 \%$,

by $33.4 \%$ for grounds with the parameter of $L>30 \%$.

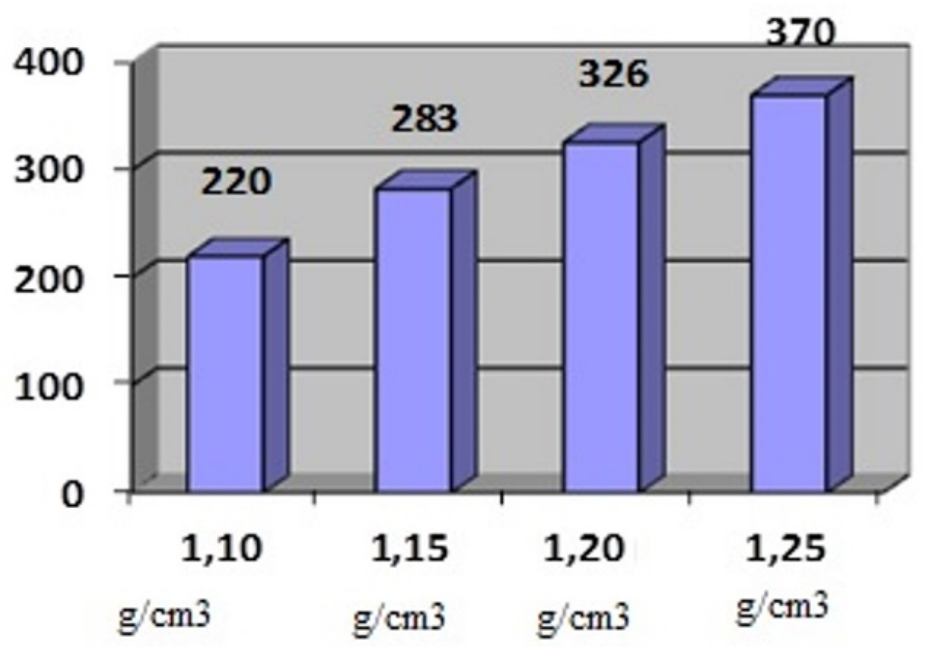

Fig. 2. The graph of the change in the magnitude of deformations of the ground mass under various calculation schemes.

This clearly indicates a qualitative improvement in the state of the ground mass after its fixation according to the recommended formulas. After carrying out works aimed at improving the structural properties of the ground mass contaminated with industrial effluents of peracetic acid the deformations of grounds are almost equal to the deformations in their natural state.

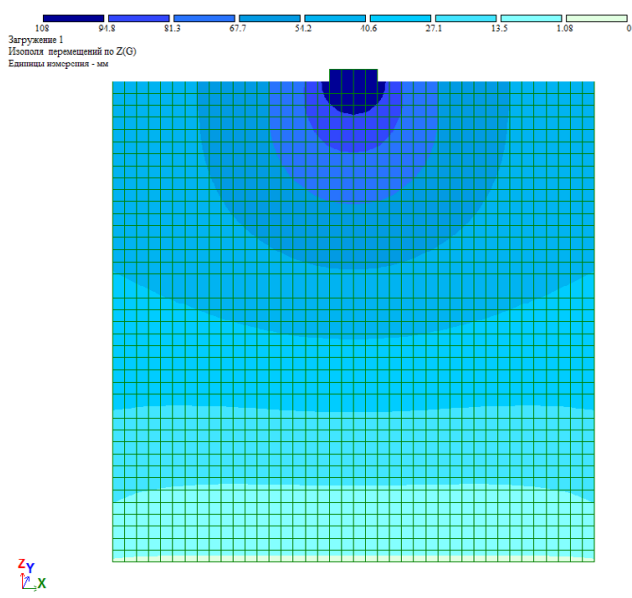

a)

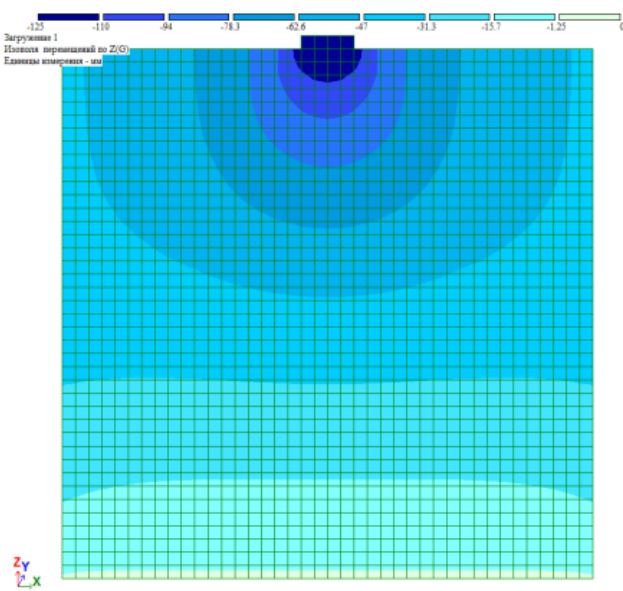

b)

Fig. 3. Vertical shifts of the ground mass: a) CS-1; b) CS-2 


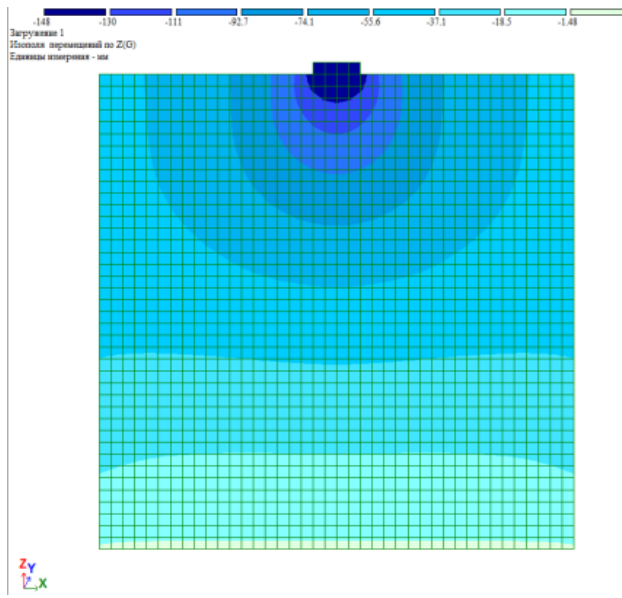

c)

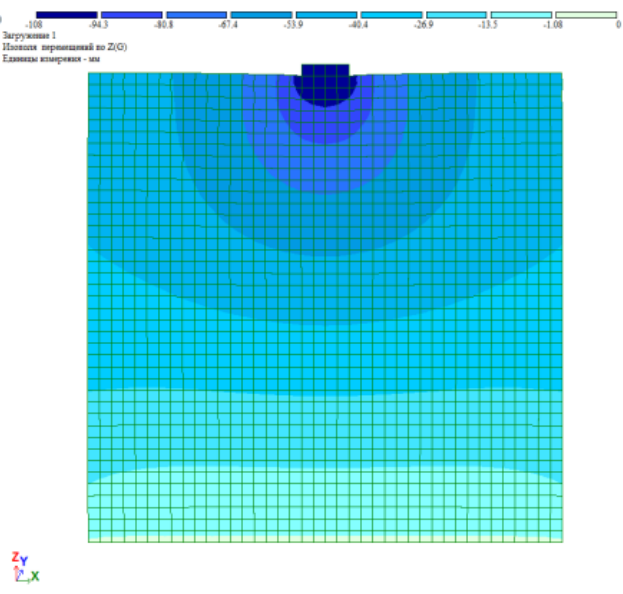

d)

Fig. 4. Vertical shifts of the ground mass: c) CS-3; d) CS-4

\section{Conclusion}

1. The evaluation of the stress-strain state of the ground mass contaminated with peracetic acid is performed.

2. As a result of the computer modeling of the ground mass contaminated with the solutions of peracetic acid it is determined that after the fixation of grounds with silicization, the value of deformations decreases by $26.11-48.9 \%$ depending on the ground base type.

3 . The comparison of the results of stress calculations indicates the stress reduction in the ground mass in $1.8-2.6$ times after its fixing.

\section{References}

1. G. Radhakrishnan, Dr M. Anjan Kumar. Dr GVR Prasada Raji. American Journal of Engineering Research, 03(04), 245-250, (2014)

2. Patil B.M., Patil K.A. Facta Universitatis Series: Architecture and Civil Engineering 11(3), 231-236 (2013)

3. DBN A.2.1-1-2008 Inzhenernyie izyiskaniya dlya stroitelstva Kiev, (2008)

4. DSTU B V.2.1-3-96 (GOST 30416-96). Grunti. LaboratornI viprobuvannya. ZagalnI polozhennya Kiev, (1997)

5. Takahashi A., D. W. H. Fung, R. J. Jarsine. Proc. 16th Intern. Conf. Soil Mecg. And Geot. Engng. Osaca, 443-446 (2005)

6. Vinnikov Yu.L. Matematichne modelyuvannya vzaemodiyi fundamentiv $z$ uschilnenimi osnovami pri yih zvedenni ta nastupniy roboti. Poltava, PoltNTU (2004)

7. Gabibov F.G. Problemyi regulirovaniya svoystv strukturno-neustoychivyih glinistyih gruntov v osnovaniyah sooruzheniy. Baku, «ELM», (1997)

8. Voblyih V.A., Kichaeva O.V. Naukoviy vIsnik budIvnitsta. Kharkiv, HGTUSA, 23, 55-59 (2003)

9. Hrapatova I.V. svit geotehniki: naukovo-tehnichniy zhurnal, Zaporizhzhya, 2, 26-29 (2008) 